\title{
MONITORING OF THE PARTICLES ABOVE THE UNPAVED ROAD BY LIDAR TECHNIQUE
}

\author{
U. KOREN LIKAR ${ }^{1, *}$ \\ V. EICHINGER ${ }^{2}$
}

\author{
${ }^{1}$ Laboratory for Environmental Research, \\ University of Nova Gorica, \\ Vipavska 13, PO Box 301, SI-5000 Nova Gorica, Slovenia \\ ${ }^{2}$ IIHR Hydroscience and Engineering, \\ The University of lowa, \\ 523B C. Maxwell Stanley Hydraulics Laboratory, lowa City, \\ lowa 52242, USA
}

Received: 05/09/10

Accepted: 02/11/11 *to whom all correspondence should be addressed: e-mail: urska.koren@siol.net

\begin{abstract}
Basic concepts of laser-based technique LIDAR (LIght Detection and Ranging) are discussed in this article as well as advantages and disadvantages. Presented are measurements of relative particulate concentrations above an unpaved road which were performed in a rural area near the lowa City, lowa, USA. The LIDAR system used in these measurements is a small, scanning LIDAR that uses elastic backscattering to obtain information on the amount of atmospheric aerosols. In the elastic LIDAR, light scattered back towards the LIDAR system from molecules and particles in the atmosphere is collected by a telescope and is detected with a photodiode. A Big Sky Laser model CFR-200 Nd:YAG laser operating at 1.064 microns is used to generate the LIDAR's outgoing signal. The laser is attached directly to the top of a $26 \mathrm{~cm}, f / 10$ Cassegrian telescope. A series of pulses are summed to make a single scan. A series of scans is used to build up a twodimensional map of relative atmospheric aerosol concentrations. With a maximum range of about 6-8 $\mathrm{km}$, a range resolution of $2.5 \mathrm{~m}$, and a time resolution of $30 \mathrm{~s}$, the LIDAR is capable of very detailed mapping of aerosols.
\end{abstract}

KEYWORDS: LIDAR technique, particulate concentration, traffic emissions.

\section{INTRODUCTION}

Air pollution is not a new phenomenon. Actually, first written records date back to the Middle Ages. At that time smoke from burning coal was already considered such a serious problem that in 1307 , King Edward I banned its use in limekilns in London. In more recent times, though still decades ago, several serious episodes focused attention on the need to control the quality of the air we breathe. The worst of these occurred in London, in 1952. A week of intense fog and smoke resulted in over 4000 excess deaths that were directly attributed to the pollution of air. In the United States the most alarming episode occurred during a four-day period in 1948 in Donora, Pennsylvania, when 20 deaths and almost 6000 illnesses were linked to air pollution (Masters, 1997). Transport becomes a significant source of air pollution after the problems of sooty smog from coal combustion had largely been solved in Western Europe and North American cities. Since then, emissions from road transport have been partly responsible for acid deposition, stratospheric ozone depletion and climate change. Road traffic exhaust emissions have been the cause of much concern about the effects of urban air quality on human health and tropospheric ozone production (Colvile et al., 2001).

Today, road transport is recognized as the major anthropogenic pollution source in urban areas worldwide (Montserrat and Baldasano, 1996). This results from the widespread use of gasoline as motor fuel. Automobile exhaust was recognized as a potential air pollutant around 1915, however it was not until about 1945 that the first urban air pollution problem definitely attributable to 
automobile emissions appeared in Los Angeles (Degobert, 1995). This type of air pollution now occurs worldwide in any urban area in which there is a heavy use of automobiles.

\section{EMISSIONS FROM AUTOMOBILES}

Emissions from mobile sources depend on the type of vehicle, speed and driving condition. Besides other pollutants automobiles produce also mineral and organic particles. Mineral dust is generated by travelling on soils and roadways. Another source of automotive mineral particles is the wearing of brake and clutch linings that contain a certain amount of asbestos fibres (Westerlund and Johansson, 2002). Organic particles result from the incomplete combustion of motor fuels due to mixtures excessively rich with gasoline. These emissions are generated mainly by diesel engines (Degobert, 1995).

Currently, there are three principal methods to estimate traffic emissions, which vary mainly in the way they treat the interaction between vehicle operation and the corresponding emissions. The first one is the simplest and only takes into account the total number of kilometers driven by the whole fleet. The second method is an average speed-dependent approach and exploits the fact that average emissions over a trip vary according the average speed of the trip. The third approach, more complex, is called instantaneous vehicle emissions and takes into account the speed variation along the trip (Delgado et al., 2000). However, all three methods reflect only the average case and will never reveal details of a specific situation, as for example near traffic lights or at train crossings. Work has been done to show that molecular concentrations change by factors of several near traffic lights and may change by an order of magnitude during stoppages (Eichinger and Kraye, 1998).

As emissions from mobile sources vary considerably from vehicle to vehicle, from driver to driver, and under various driving conditions, even the most careful simulation will only reflect the average case, and will never reveal details of a specific situation.

\section{LIDAR TECHNIQUE}

\section{Principles and Instrumentation}

To evaluate pollution levels from roads, not just in average case, but in shorter time intervals, advanced techniques for monitoring air pollutants are needed. Laser-based techniques, such as Light Detection And Ranging (LIDAR), proved to be a very efficient tool for this purpose (Sigrist, 1994). The LIDAR technique is based on the scattering of laser light on particles and molecules in the atmosphere. First, laser pulses are emitted into the atmosphere and then the backscattered radiation is collected and analysed.

Discovered in the early 1960s, lidars have been used to measure wind velocity in storms near airports (Zbigniew, 1989). Lidars have also proved useful in defining the temporal and spatial distribution of airborne particles, measuring temperature and humidity (Zuev, 1995).

The LIDAR technique has some distinct advantages over conventional in-situ methods, which take samples at a single point. The sampling procedure may influence the concentration in in-situ measurements, and furthermore, the instruments may accidentally be placed where sudden local maxima or minima make the measurements non-representative. LIDAR measurements are performed over long distances along any direction, which makes them less sensitive to local fluctuations (Goers, 1995). It is possible to chart the concentration in a large volume around the point of interest, which would otherwise require a large number of point measuring stations. Furthermore, data from parts of the atmosphere, which are otherwise hard to reach, can be obtained easily. The system's non-intrusive nature and real-time data capability make it particularly useful. Disadvantages are the high costs of the system and difficulties in inverting the absolute concentrations of particles.

A LIDAR system is a laser remote sensor, consisting of a transmitting laser source and an optical receiver, which is used to collect the light that is backscattered on particles or molecules in the air. Illustration of a general configuration of the LIDAR system is presented in Figure 1. In the figure the laser source and the receiver are at the same location and the system is biaxial; that means that the laser beam is emitted beside the axis of the receiver telescope. In a coaxial system the laser beam coincides with this axis (Measures, 1988). 


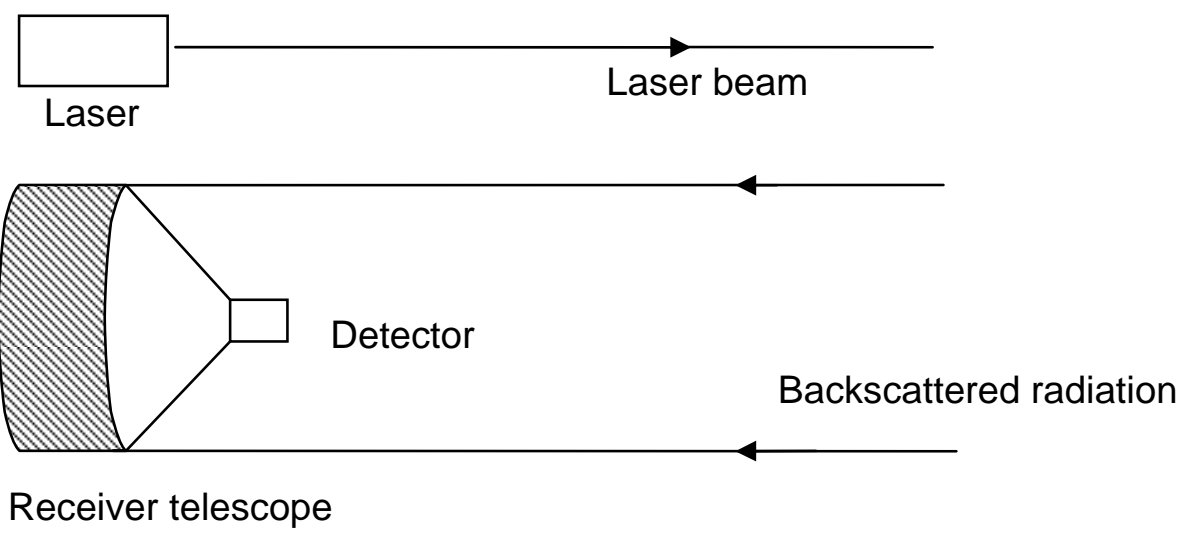

Figure 1. Configuration of biaxial LIDAR system.

\section{LIDAR Equation}

The received power of the elastically backscattered radiation from a distance $r$ can be described by the LIDAR Equation (Measures, 1988)

$$
P(\lambda, r)=C(\lambda, r) \frac{A_{r}}{r^{2}} P_{0}(\lambda) \frac{c \tau}{2} \beta(\lambda, r) \exp \left(-2 \int_{0}^{r} \alpha\left(\lambda, r^{\prime}\right) d r^{\prime}\right)
$$

In Equation (1), $C(\lambda, r)$ is a function determined by the geometric considerations of the receiver optics, the quantum efficiency of the detection system at wavelength $\lambda$, and the overlap of the emitted laser beam with the field of view of the receiver. The term $A_{r} r^{-2}$ is the acceptance solid angle of the receiver optics with collecting area $A_{r}$. The emitted power of a laser pulse at wavelength $\lambda$ is written as $P_{0}(\lambda), c$ is the velocity of light and $\tau$ is the pulse duration. $\alpha(\lambda, r)$ is the attenuation coefficient and $\beta(\lambda, r)$ the backscattering coefficient

$\beta(\lambda, r)=\sum_{i} \sigma_{B_{i}}(\lambda) N_{i}(r)$,

where $B_{i}(\lambda)$ is the backscattering cross-section at wavelength $\lambda$ and $N_{i}(r)$ represents the number density of scatterer species $i$.

Since it is reasonable to assume that molecular backscattering is negligible in the infrared region, and that particulate backscattering dominates in this region, the LIDAR signal gives particle backscatter information directly if laser is operating in this region. By assuming a relationship between aggregate particle backscatter and particulate mass or number density, the LIDAR signal can be used in semiquantitative manner to monitor and track particle concentrations (Holmen and Eichinger, 2001).

\section{MONITORING OF THE PARTICLES ABOVE THE UNPAVED ROAD}

\section{Measurement Location}

Measurement location was selected to meet three requirements:

- LIDAR site located at least $300 \mathrm{~m}$ away from the road, which was a subject of the research,

- no trees or other higher obstacles between the LIDAR site and the road,

- the wind blowing mainly in the direction perpendicular to the road.

The measurement site was selected in a rural area close to lowa City. The LIDAR system was located at the $520^{\text {th }}$ Street, about $700 \mathrm{~m}$ away from the White Oak Avenue. White Oak Avenue is a local, unpaved road crossing the agricultural fields of soya bean and corn. The terrain is flat. The LIDAR was pointing in direction $80^{\circ}$ from the North. A schematic view of the site is presented in Figure 2. 


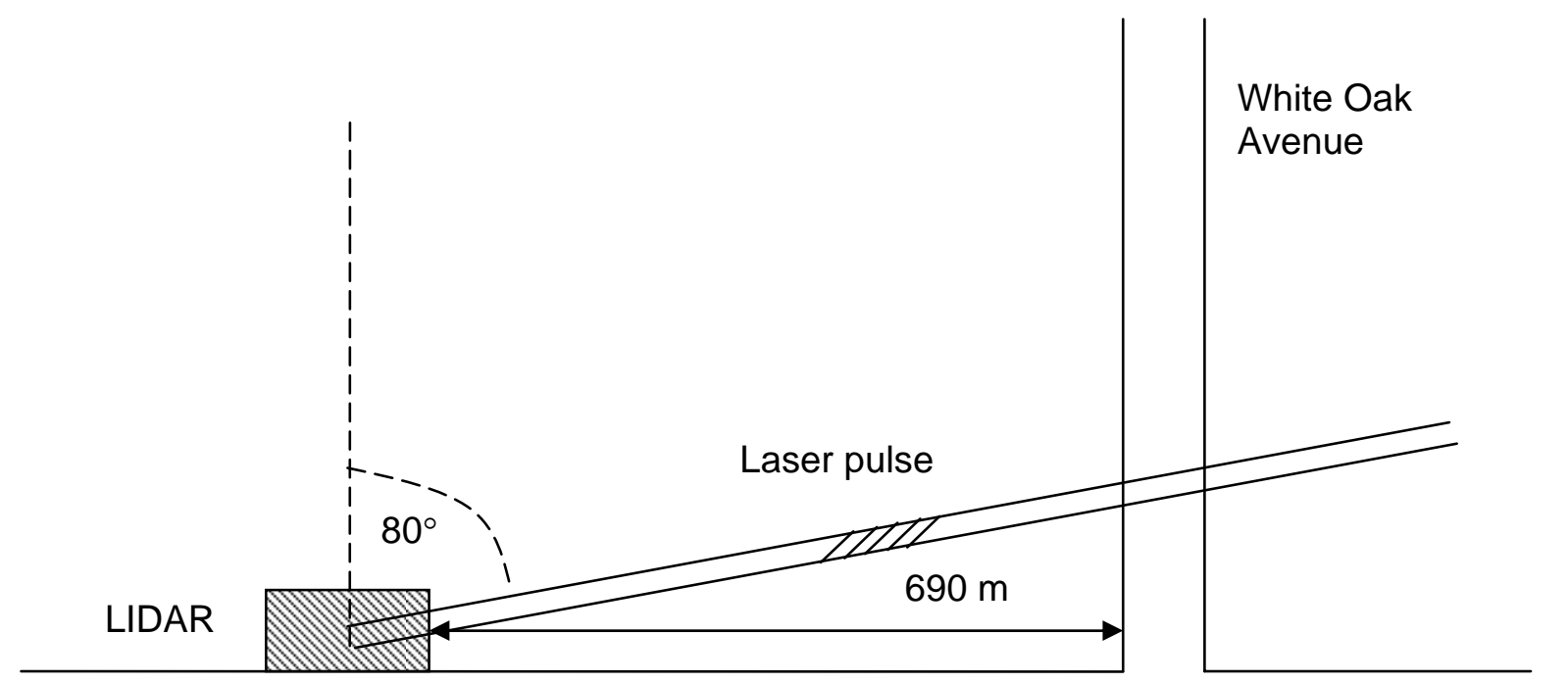

520th Street

Figure 2: Cheme of the measurement location in the rural area near lowa City.

\section{Experimental Instrumentation}

The LIDAR system used in experiment is a small, scanning LIDAR that uses elastic backscattering to obtain information on the amount of atmospheric aerosols (Holmen and Eichinger, 2001).

In the elastic LIDAR, light scattered back towards the LIDAR system from molecules and particles in the atmosphere is collected by a telescope and is detected with a photodiode.

There are three main components of a LIDAR system: laser, telescope, and detector. A Big Sky Laser model CFR-200 Nd:YAG laser operating at 1.064 microns is used to generate the LIDAR's outgoing signal. The laser requires continuous water cooling which is provided by the cooler unit and the entire laser system is controlled by the Model 8800-13 "Laser Controller" power supply unit via a menu-driven operating system. The laser operates at a repetition rate of $50 \mathrm{~Hz}$ and has a maximum output of $124 \mathrm{~mJ}$. Pulses are of about $10 \mathrm{~ns}$ duration, the beam diameter is about 0.7 $\mathrm{cm}$, and beam divergence (full angle) is about $3.0 \mathrm{mrad}$.

The laser is attached directly to the top of a $26 \mathrm{~cm}$, f/10 Cassegrian telescope. The laser beam is emitted parallel to the telescope after going through a periscope, so that the effective exit aperture is $41 \mathrm{~cm}$ from the centre of the telescope. The periscope simplifies alignment, and also increases the distance over which the laser beam overlaps with the telescope's field of view. This separation decreases the chance of near-field detector overloading, and decreases the dynamic range required for the analog-to-digital conversion system. A good laser-telescope alignment is reached when laser beam is positioned as close to parallel position as possible, relative to the telescope's field of view. A camera is mounted on the top of the periscope. It captures the image of the area near the telescope's field of view.

The telescope-laser system is able to turn rapidly through 180 degrees horizontally and 90 degrees vertically, using computer-controlled motors incorporated into the telescope mount. The LIDAR scanning azimuth range is therefore from 0 to 180 degrees.

The elevation range is 0 degrees when the telescope points horizontally, and up to 90 degrees when it points straight up.

Behind the telescope, the light passes through the interference filter and a lens system that focuses the light on a photodiode. Two detectors mounted in the periscope sample the outgoing laser pulse and produce signals which are used to correct for pulse-to-pulse variations in the laser energy and also serve as a timing marker to start the digitization process. 
The system is capable of 24-hour-a-day operation through the use of a 3-nm wide interference filter, well-blocking the visible and near infrared, with a peak transmission of 52 percent. The LIDAR set-up used in our measurements is presented in Figure 3.

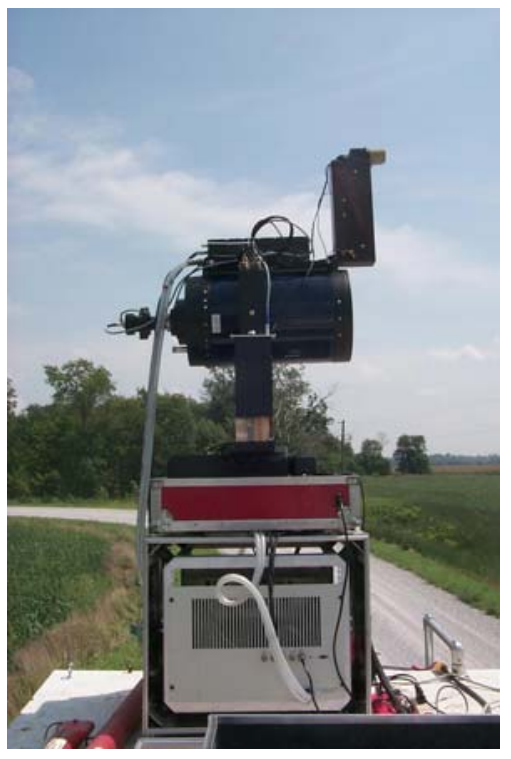

Figure 3: The LIDAR set-up. The major components are: laser, telescope, detector, periscope, camera, laser cooler and power supply.

A series of pulses are summed to make a single scan. A series of scans is used to build up a twodimensional map of relative atmospheric aerosol concentrations. With a maximum range of about 6-8 $\mathrm{km}$, a range resolution of $2.5 \mathrm{~m}$, and a time resolution of $30 \mathrm{~s}$, the LIDAR is capable of very detailed mapping of aerosol concentrations. Furthermore, the scattering of $1.064 \mu \mathrm{m}$ wavelength results predominantly from particles between roughly 0.5 and $5 \mu \mathrm{m}$ diameter.

The distance $d$ which the laser pulse, emitted by the LIDAR, travels from the LIDAR is $d=\frac{1}{2} c t$,

where $c$ is the speed of light and $t$ the time interval between the emitted and the received pulse. The factor $1 / 2$ is introduced since the laser pulse must return to LIDAR to be detected, so it travels the distance $d$ twice.

The laser outgoing pulse pulses at a $50 \mathrm{~Hz}$ repetition rate, so the time between each laser pulse is $20 \mathrm{~ms}$. The maximum range is then (Equation (3))

$d=\frac{1}{2} \cdot 3 \cdot 10^{8} \mathrm{~ms}^{-1} \cdot 20 \cdot 10^{-3} \mathrm{~s}=3000 \mathrm{~km}$.

In practice, many consequent pulses are averaged to increase the signal to noise ratio, which results in longer data acquisition time.

The LIDAR range resolution depends on the distance which the laser pulse travels between sampling events. Knowing the sampling period, which tells us how often the photodetector output is sampled, enables the range resolution to be calculated from Equation (3).

\section{RESULTS}

Road dust is more than simple dirt a vehicle stirs up as it moves along the road. Besides dirt from soil, road dust also contains the suspended fine particulate matter created from tail pipe emissions.

To get the information about such kind of pollution the measuring site in rural area outside the lowa City was selected. A local unpaved road crossing an agriculture field was an interesting point for that. Vertical LIDAR scans were done above White Oak Avenue, which was about $700 \mathrm{~m}$ away from the LIDAR site. Measurements were taken on the $30^{\text {th }}$ of August, 2002, in the afternoon. Vertical scans were taken every 40 seconds. Range-corrected signal averaged over 15 
consecutive laser shots directed at angle of $0.8^{0}$ above White Oak Avenue is shown in Figure 4. Increased signal is observed at about $700 \mathrm{~m}$ caused by a car passing by.

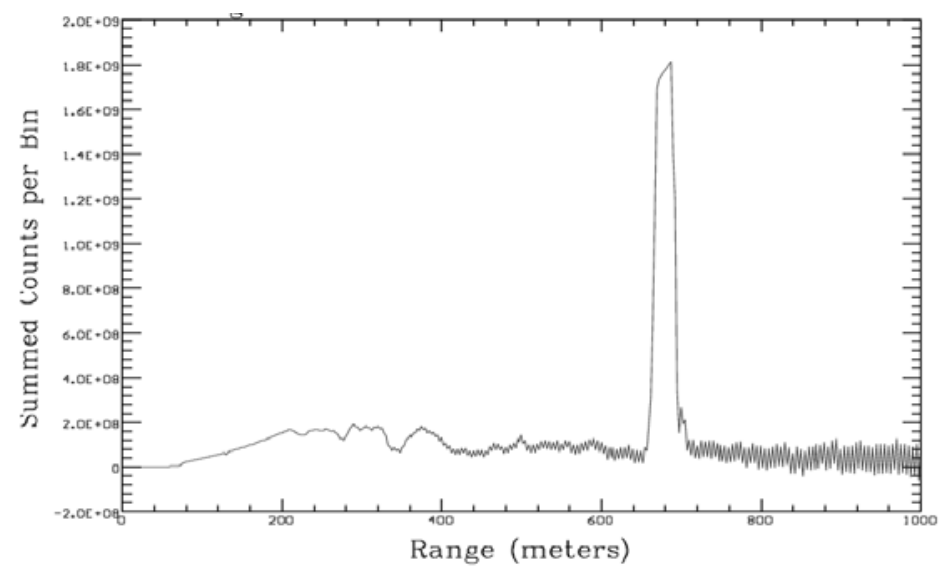

Figure 4: The range-corrected signal over White Oak Avenue. The increased signal due to backscattering is observed at about $700 \mathrm{~m}$.

Plumes of particulate matter were moving toward the LIDAR site as the wind was blowing in this direction. This movement can be observed in Figures 5 and 6. In Plot (a) of Figure 5 taken at 13:15:24, there is no sign of particles above the road, in Plot (b) taken at 13:16:04, higher particle concentration is detected above $650-700 \mathrm{~m}$. The plume is approximately $15 \mathrm{~m}$ high. It is moving towards the LIDAR, being less intense on another Plot (c) taken at 13:16:44. A Plot (d) of Figure 5 and Plots (a) and (b) of Figure 6 show further moving towards the LIDAR and also raising of a plume. In Plot (c) of Figure 6 taken at 13:19:24 already new plume is developing at around $700 \mathrm{~m}$, caused by another car passing by. In Plot (d) at 13:20:04 the new plume is raising and moving towards the LIDAR site, and also traces of the first plume can be seen at $300-400 \mathrm{~m}$. The new plume is surprisingly high (up to $55 \mathrm{~m}$ ). It is probably caused by turbulence generated by cars.

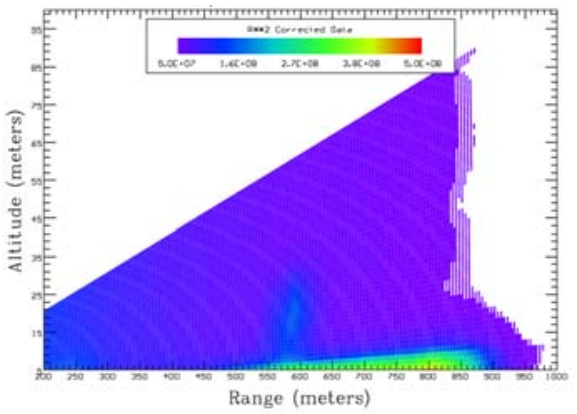

(a)

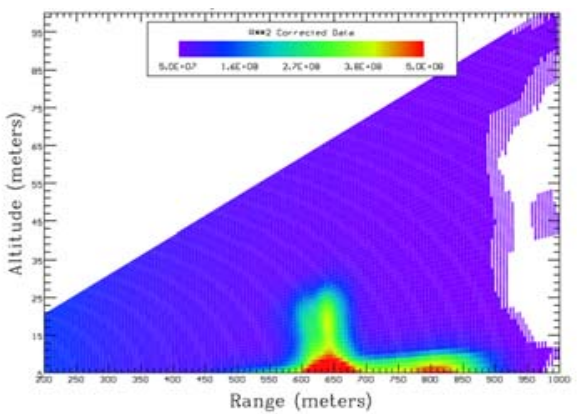

(c)

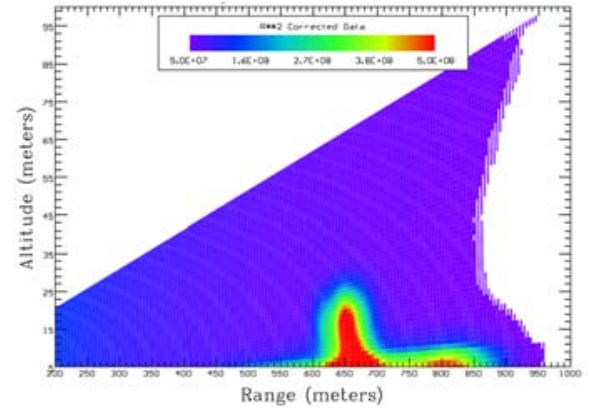

(b)

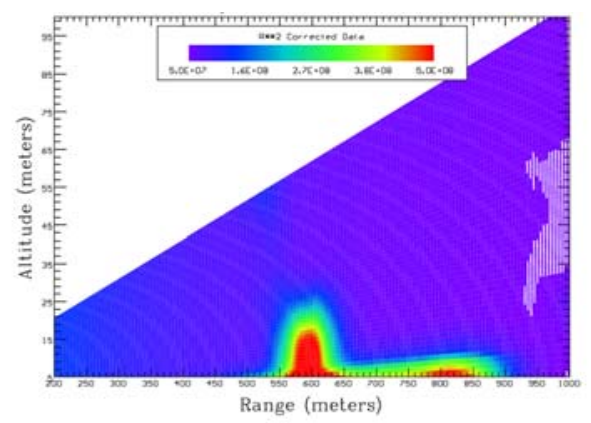

(d)

Figure 5: Vertical LIDAR scans above White Oak Avenue taken in time intervals of 40 seconds from 13:15:24 to $13: 17: 24$. 


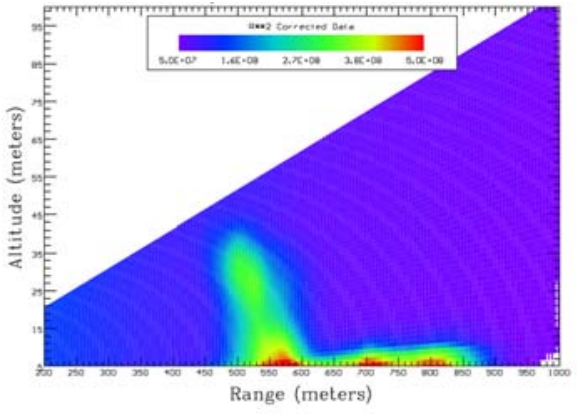

(a)

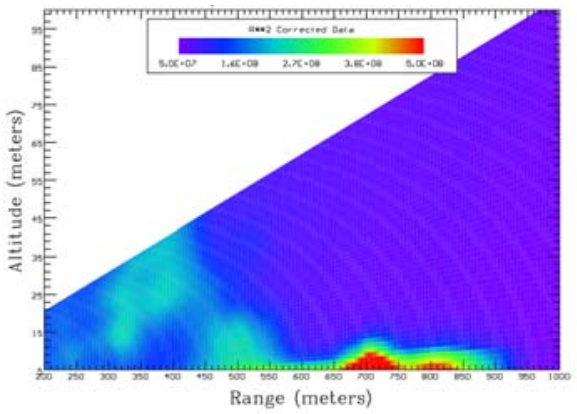

(c)

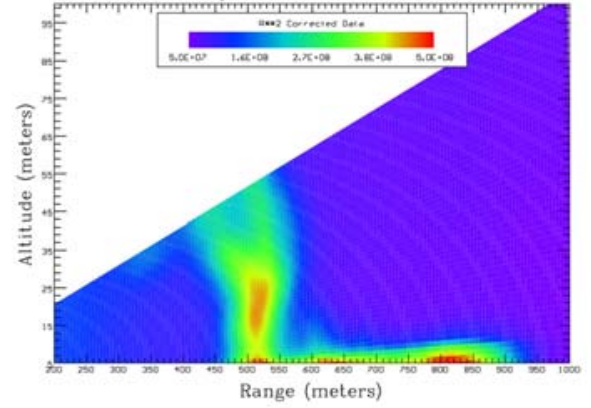

(b)

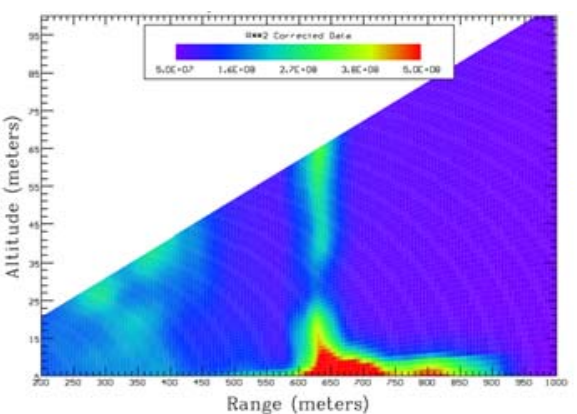

(d)

Figure 6: Vertical LIDAR scans above White Oak Avenue taken in time intervals of 40 seconds from 13:18:04 to $13: 20: 04$.

\section{CONCLUSION}

As the number of automobiles worldwide is increasing, the pollution from them become a serious problem. Due to complexity of this problem, advanced methods for monitoring are needed. One of them is laser-based LIDAR technique. Lidars can provide a three-dimensional picture of atmospheric pollutants. With their high temporal resolution, lidars give the insight into the causes of locally high concentrations. They provide detailed information on the relative magnitudes and locations of air pollution sources and directions of dispersion. That is why it can be used to effectively identify the source and extend of particle pollution above roads.

\section{ACKNOWLEDGEMENTS}

The authors would like to thank prof. dr. Mladen Franko and prof. dr. Andrej Filipcic from University of Nova Gorica.

\section{REFERENCES}

Colvile R.N., Hutchinson E.J., Mindell J.S. and Warren R.F. (2001), The transport sector as a source of air pollution, Atmospheric Environment, 35, 1537-1565.

Degobert P. (1995), Automobiles and pollution, Society of Automotive Engineers, Inc., Warrendale, PA, USA.

Delgado R., Toll I., Soriano C. and Baldasano J.M. (2000), In: Advances in air pollution: Air Pollution VIII, WITpress, Southampton.

Eichinger W. and Kraye H. (1998), The use of LIDAR to evaluate existing incident managment system on I-80 in Morris, Essex, and Passaic Counties in Northern New Jersey, Report No. 980004l_7290, New Jersey Department of Transportation.

Goers U.B. (1995), Laser remote sensing of sulfur dioxide and ozone with mobile differential absorption LIDAR ARGOS, Optical Engineering, 34, 3097-3102.

Holmen B.A. and Eichinger W. (2001), Miniature Elastic LIDAR - Standard Operating Procedure, Crocker Nuclear Laboratory, University of lowa.

Masters G.M. (1997), Introduction to Environmental Engineering and Science, Prentice Hall.

Measures R.M. (1988), Laser Remote Chemical Analysis, John Wiley \& Sons, New York. 
Montserrat C. and Baldasano J.M. (1996), Development of a source emission model for atmospheric pollutants in the Barcelona area, Atmospheric Environment, 30, 309-318.

Sigrist M.W. (1994), Air Monitoring by Spectroscopic Techniques, John Wiley \& Sons, New York.

Westerlund K.G. and Johansson C. (2002), Emissions of metals and particulate matter due to wear of brake linings in Stockholm, In: Advances in Air Pollution: Air pollution X, WITPress, Southampton.

Zbigniew S. (1989), Structure of the Atmospheric Boundary Layer, Prentice Hall, Englewood Cliffs, New Jersey.

Zuev V. (1995), Laser remote sensing of meteorological and ecological parameters of the atmosphere, In: Workshop on Optical Methods for Environmental Monitoring of the Atmosphere, Tomsk, Russia. 